Dhaka Univ. J. Sci. 60(2): 195-198, 2012 (July)

\title{
Synthesis of Cyclohexylcresols by Alkylation of Cresols with Cyclohexanol in the Presence of Perchloric Acid
}

\author{
Md. Ashaduzzaman*, A. M. Sarwaruddin Chowdhury and Manoranjan Saha \\ Department of Applied Chemistry and Chemical Engineering, \\ University of Dhaka, Dhaka 1000, Bangladesh \\ * E-mail: azaman.du@gmail.com
}

Received on 14. 06. 2011. Accepted for Publication on 01. 12. 2011.

\begin{abstract}
Cyclohexylcresols were synthesized in high yield by the alkylation of cresols with cyclohexanol in the presence of perchloric acid as catalyst. The effects of the variation of temperature, molar ratio of cresol to cyclohexanol, time of reaction and amount of catalyst on the reactions were also extensively studied. The products were confirmed by spectral means and physicochemical constants.
\end{abstract}

Keywords: Cyclohexanol, Perchloric acid, Cresol, Cyclohexylcresol

\section{Introduction}

During the last few decades, much attention has been directed to the synthesis of organic compounds with exciting properties for practical applications. Alkylation is one of the most popular techniques for transferring of an alkyl group from one molecule to another to produce new molecules. Among the alkylation reactions, alkylation of cresols is very important. Alkylated cresols and their derivatives are the most effective antioxidants and multifunctional stabilizers in fuels, lubricating oils and wide variety of oxygen sensitive materials. ${ }^{1,2}$ Moreover, some of the derivatives of the alkyl cresols exhibit promising characteristics due to the strong herbicidal, bactericidal and insecticidal activities. ${ }^{1,3}$

Alkylated cresols have been synthesized by several authors by alkylation of isomeric cresols with alkenes ${ }^{4-11}$ and alcohols $^{12-19}$ using different protic and aprotic acids. In 1968, Babakhanov et al. ${ }^{4}$ reported cycloalkylation of $m$ cresol by cycloolefins using sulfuric acid catalyst. In 1992, Saha et al. ${ }^{13}$ reported alkylation in presence of sulfuric acid for the reaction of $m$-cresol with cyclohexanol. Moreover, in 1995, Saha et al. ${ }^{18}$ further reported alkylation of $o$-cresol with $n$-alcohols using sulfuric acid as catalyst. But studies on the reactions of cresols with alcohols in the presence of perchloric acid have not yet been reported from any research group.

In the present work, alkylation of isomeric cresols with cyclohexanol in the presence of perchloric acid as catalyst has been investigated.

\section{Materials and Methods}

All reactants and reagents were purchased from Merck, Germany and used without further purification. The reactions were carried out in a three necked round bottomed flask fitted with a stirrer, a condenser, a thermometer and a dropping funnel. Cresol (ortho-, meta- or para-cresol) and perchloric acid were charged into the flask and heated to the desired temperature and cyclohexanol was introduced dropwise to the mixture for a certain period of time (time of addition) with constant stirring. After the addition of the total amount of cyclohexanol, the reaction mixture was stirred for another 1 to $2 \mathrm{~h}$ (time of stirring) at the same temperature. The reaction mass was then cooled, dissolved in ether and neutralized. The reaction mixture was then washed with distilled water several times and subjected to distillation. Unreacted reactants and solvent were distilled off at atmospheric pressure. Products thus obtained were distilled and characterized by spectral means.

\section{Results and Discussion}

The reactions of meta-cresol with cyclohexanol in the presence of perchloric acid were investigated over the temperature range of 60 to $140^{\circ} \mathrm{C}$. Molar ratio of $m$-cresol to cyclohexanol was varied from $4: 1$ to $8: 1$, amount of perchloric acid from 1 to $5 \%$ by wt. of $m$-cresol, time of reaction from 1 to $4 \mathrm{~h}$. Cyclohexylcresols were obtained as the reactions product as shown in Figures 1-4. It is revealed that the yield of the products increased with the increase of temperature, molar ratio of $m$-cresol to cyclohexanol, amount of perchloric acid and time of reaction. Thus, the following conditions are considered as optimum for the production of cyclohexyl $m$-cresol in $97.8 \%$ yield: temperature $=140^{\circ} \mathrm{C}$, molar ratio of $m$-cresol to cyclohexanol $=8: 1$, amount of perchloric acid $=5 \%$ by wt. of $m$-cresol, time of addition $=2 \mathrm{~h}$ and time of stirring $=2 \mathrm{~h}$.

After obtaining, the optimum conditions for maximum yield of cyclohexyl- $m$-cresol, we carried out another alkylation reaction using $p$-cresol instead of $m$-cresol. The yield of 2cyclohexyl-4-methylphenol was $96.4 \%$, under the optimum conditions of the reaction of $m$-cresol with cyclohexanol.

\footnotetext{
* Correspondence author :
} 


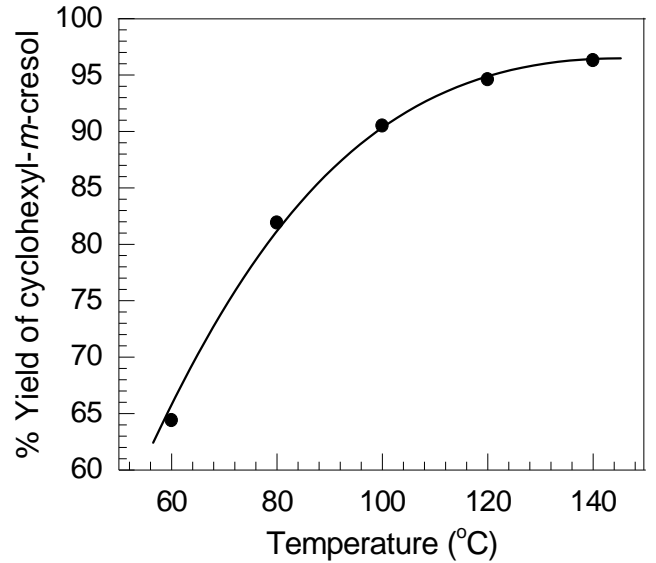

Fig. 1. Effect of the variation of temperature on the reaction of $m$ cresol with cyclohexanol in the presence of perchloric acid (molar ratio of $m$-cresol to cyclohexanol $=8: 1$, amount of perchloric acid $=$ $5 \%$ by wt. of $m$-cresol, time of addition $=2 \mathrm{~h}$, time of stirring $=1 \mathrm{~h}$ ).

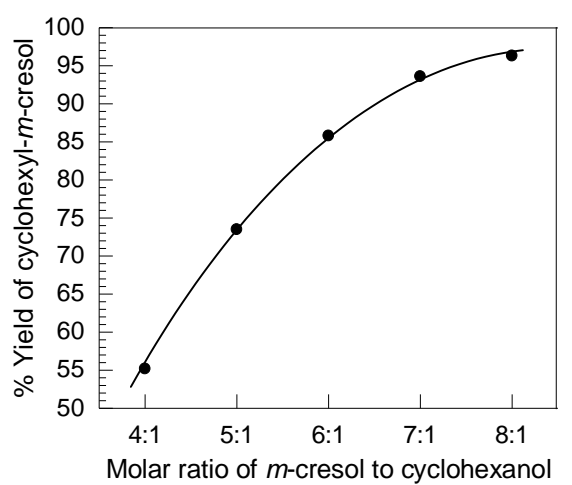

Fig. 2. Effect of the variation of molar ratio of $m$-cresol with cyclohexanol in the presence of perchloric acid (temperature = $140^{\circ} \mathrm{C}$, amount of catalyst $=5 \%$ by wt. of $m$-cresol, time of addition $=2 \mathrm{~h}$, time of stirring $=1 \mathrm{~h}$ ).

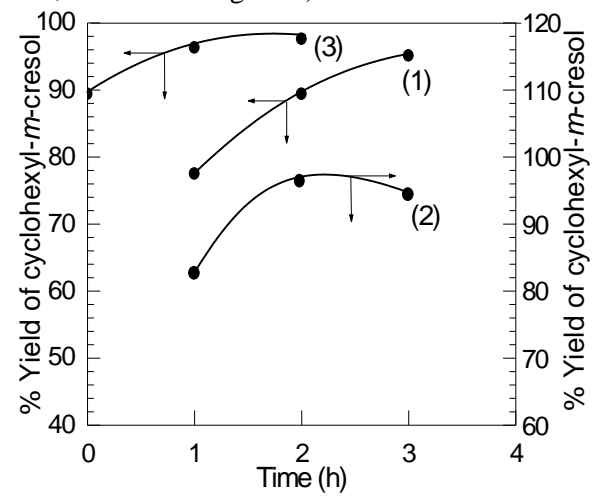

Fig. 3. Effect of the variation of amount of catalyst (perchloric acid) on the reaction of $m$-cresol with cyclohexanol (temperature = $140^{\circ} \mathrm{C}$, molar ratio of $m$-cresol to cyclohexanol $=8: 1$, amount of perchloric acid $=5 \%$ by wt. of $m$-cresol, time of addition $=2 \mathrm{~h}$, time of stirring $=1 \mathrm{~h}$ ).

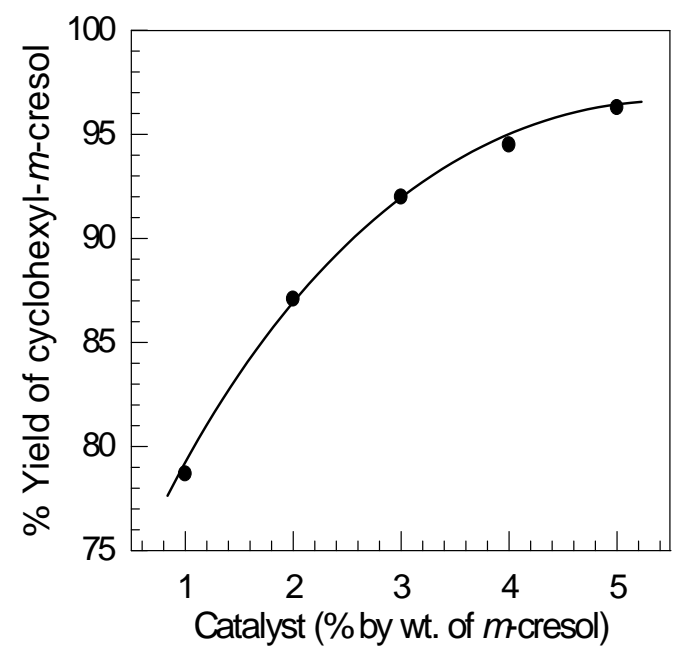

Fig. 4. Effect of the variation of time on the yield of cyclohexyl-mcresol (temperature $=140^{\circ} \mathrm{C}$, molar ratio of $m$-cresol to cyclohexanol $=8: 1$, amount of catalyst $=5 \%$ by wt. of $m$-cresol): 1. Time of stirring $=0 \mathrm{~h}, 2$. Total time of reaction $=3 \mathrm{~h}$ and 3 . Time of addition $=1 \mathrm{~h}$

Recently, we reported a mathematical model $^{20}$ for optimizing yield of cyclohexyl-o-cresol from alkylation of $o$-cresol with cyclohexanol in the presence of perchloric acid and the most significant influential factors to accelerate the reaction. For comparison, it is worthwhile, to mention that the best yield $89.3 \%$ of product was achieved under the following reaction conditions: temperature $=140^{\circ} \mathrm{C}$, molar ratio of $o$-cresol to cyclohexanol $=6: 1$, amount of perchloric acid $=5 \%$ by wt. of $o$-cresol, time of addition $=2 \mathrm{~h}$ and time of stirring $=1 \mathrm{~h}$.

Cyclohexyl group substitutes the aromatic ring to the orthoor para- position with respect to the $-\mathrm{OH}$ group. Therefore, the reaction of $p$-cresol with cyclohexanol gave only one product, while the reactions of ortho- and meta- cresols gave mixture of isomeric cyclohexylcresols as shown in the Scheme 1.

Tables 1 and 2, show the spectral analyses of cyclohexylcresols with FT-IR and ${ }^{1} \mathrm{H}-\mathrm{NMR}$ spectroscopy respectively. FT-IR bands for functional groups and integral area ratio of different protons in the ${ }^{1} \mathrm{H}-\mathrm{NMR}$ spectrum 


(n)

Scheme 1. Chemical structure of cresols and their respective alkylated products produced from alkylation with cyclohexanol in presence of perchloric acid.

Table. 1. FT-IR spectral analyses of cyclohexylcresols

\begin{tabular}{lccc}
\hline \multicolumn{1}{c}{ Functional group } & \multicolumn{3}{c}{ Wavenumber, $\mathrm{cm}^{-1}$} \\
\cline { 2 - 4 } & Cyclohexyl $m$-cresols & $\begin{array}{c}\text { Cyclohexyl } o \text { - } \\
\text { cresols }^{20}\end{array}$ & 2-Cyclohexyl-4-cresols \\
\hline 1,2,3-trisubstituted benzene ring & 775 & 775 & -- \\
$1,2,4$-trisubstituted benzene ring & $800-900$ & $800-900$ & $800-900$ \\
Aromatic ring & 1570 & 1570 & 1600 \\
Saturated C-H group & $2850-2920$ & $2850-2910$ & $2950-3000$ \\
-OH group & 3400 & 3420 & 3400 \\
\hline
\end{tabular}

Table. 2. ${ }^{1} \mathrm{H}$-NMR spectral analyses of cyclohexylcresols in $\mathrm{CDCl}_{3}$

\begin{tabular}{|c|c|c|c|}
\hline \multirow{2}{*}{ Responsible proton } & \multicolumn{3}{|c|}{ Chemical shift $(\delta)$ ppm } \\
\hline & $\begin{array}{l}\text { Cyclohexyl } m \text { - } \\
\text { cresols }\end{array}$ & $\begin{array}{l}\text { Cyclohexyl } o- \\
\text { cresols }^{20}\end{array}$ & $\begin{array}{l}\text { 2-Cyclohexyl-4 } \\
\text { cresol }\end{array}$ \\
\hline Three protons on the aromatic ring & $6.13-7.17$ & $6.27-7.1$ & $6.25-7.00$ \\
\hline One proton on the $-\mathrm{OH}$ group & $5.0-5.83$ & 4.48 & 6.03 \\
\hline Three protons on the $-\mathrm{CH}_{3}$ ring & $2.03-2.46$ & $2.01-2.33$ & $2.07-2.30$ \\
\hline $\begin{array}{l}\text { All protons on the cyclohexyl ring except } \\
\text { one on the } \alpha \text {-position relative to the }\end{array}$ & & & \\
\hline aromatic ring & $0.77-2.03$ & $0.94-2.06$ & $0.50-2.04$ \\
\hline One proton on the $\alpha$-position & $2.46-3.17$ & $2.33-3.23$ & $2.49-3.13$ \\
\hline
\end{tabular}


Table. 3. Physicochemical properties of cyclohexylcresols.

\begin{tabular}{lccc}
\hline Parameters & $\begin{array}{c}\text { Cyclohexyl } m \text { - } \\
\text { cresols }\end{array}$ & $\begin{array}{c}\text { Cyclohexyl } o- \\
\text { cresols }\end{array}$ & $\begin{array}{c}\text { 2-Cyclohexyl-4- } \\
\text { cresol }\end{array}$ \\
\hline Boiling point $\left({ }^{\circ} \mathrm{C}\right)$ & 300 & 298 & 310 \\
Density $\left(d_{4}^{2 D}\right)$ & 1.0246 & 1.0093 & 1.0054 \\
Refractive index $\left(n_{D}^{20}\right)$ & 1.5435 & 1.5340 & 1.5345 \\
\hline
\end{tabular}

confirmed the products. 2-Cyclohexylcresols gave characteristic values of boiling point, density and refractive index which are presented in Table 3 . Since alkylation is one of the most effective routes for synthesis of new molecules, the performance of perchloric acid as a catalyst for production of cyclohexylcresols would be a new crucial goal in terms of economic, academic and fundamental researches.

1. Lebedev, N. N., 1984. Chemistry and Technology of Basic Organic and Petroleum Synthesis. Mir Publishers, Moscow. 638.

2. Ravikovich, A. M., 1964. Antioxidants for mineral and synthetic lubricating oils. Chemistry and Technology of fuels and oils. 11: 68-71.

3. Melinikov, N. N., Y. A. Baskakov and K. S. Bokrev, 1954. Chemistry of Herbicides and Plants Growth Regulators. Gkhi. Moskow. 38.

4. Babakhanov, R. A., S. G. Gasanova, A. V. Bakunina and M. A. Salimov, 1968. Cycloalkylation of $m$-cresols by cycloolefins in the presence of sulfuric acid. Azer. Khim. Zh. 1: 36-39.

5. Saha, M., M. B. Zaman and N. Nahar, 1994. A study of alkylation of cresols with cyclopentene. Nuclear Science and Applications. 3(2): 19-22.

6. Saha, M., S. Saha and M. Mosihuzzaman, 1996. Alkylation of $p$-cresol with cyclohexene in the presence of sulfuric acid. Indian Journal of Chemical Technology. 3: 292-294.

7. Saha, M., S. Chowdhury, M. A. B. Sarker, Y. N. Jolly and D. Saha, 1997. A study of alkylation of cresols with cyclooctene. Bangladesh J. Sci. Ind. Res. 32(1): 63-66.

8. Saha, M. and M. Mosihuzzaman, S. Saha and S. K. Gosh, 1998. Alkylation of $m$-cresol with cyclohexene in the presence of benzenesulphonic acid. Bangladesh J. Sci. Ind. Res. 33(1): 17-19.

9. Saha, M., H.M.N.E. Mahmud, S. K. Ghosh, M. D. Zaman, D. Saha, and S. K. Saha, 2000. Cycloalkylation of $p$-cresol with cycloalkenes in the presence of borontrifluoride etherate. Bangladesh J. Sci. Res. 18(2): 273-276.
10. Saha, M., H. M. N. E. Mahmud, S. K. Ghosh, M. D. Zaman, D. Saha and M. A. Hasan, 2000. Reaction of $o$-cresol with cyclohexene in the presence of borontrifluoride etherate. Bangladesh J. Sci. Res. 18(2): 335-337.

11. Saha, M. and S. K. Ghosh, 1989. Cyclohexylation of $m$ cresol. Bangladesh. J. Sci. Res. 7(2), 273-275.

12. Saha, M. and R. K. Roy, 1988. Cycloalkylation of $o$-cresol with hexanol. Bangladesh. J. Sci. Res. 6, 73-81.

13. Saha, M. and R. K. Roy, 1992. Alkylation of $m$-cresol with cyclohexanol in the presence of sulfuric acid. Bangladesh. $J$. Sci. Ind. Res. 27(3-4): 23-29.

14. Saha, M, and M. B. Badruzzaman, 1992. Alkylation of $p$ cresol with octanol-1 in the presence of sulfuric acid. $J$. Bangladesh Chem. Soc. 5(2): 227-230.

15. Saha, M., S. Biswas, and D. Saha, 1994. Cycloalkylation of $p$ cresol. J. Bangladesh Academy of Science. 18(1): 29-32.Vol. 119.

16. Saha, M.; D. Saha, S. Biswas, and M. B. Zaman, 1995. Alkylation of $p$-cresol with cyclopentanol. Bangladesh J. Sci. Ind. Res. 30(2-3): 21-27.

17. Saha, M., Y. N. Jolly, D. Saha, and M. A. B. Sarker, 1997. Alkylation of $p$-cresol with n-alcohols. Bangladesh J. Sci. Ind. Res. 32(1): 67-69.

18. Saha, M., and P. K. Basak, 1995. Aklylation of $o$-cresol with $n$-alcohols in the presence of sulfuric acid. Research Publication of Bose Centre for Advanced Study and research in Natural Sciences, 92-102.

19. Saha, M., P. K. Basak, D. Saha and M. Z. Alam, 2000. Alkylation of $m$-cresol with $n$-alcohols in the presence of sulfuric acid. Bangladesh J. Sci. Res. 18(1): 95-102.

20. Ashaduzzaman, M., Saha. M., Islam, S. T. A., Ismail, M., Sharif, N. and Galib, M. 2009. A mathematical model for alkylation of o-cresol with cyclohexanol. Bangladesh J. Sci. Ind. Res. 44(2): 181-186. 
